Contract No. and Disclaimer:

This manuscript has been authored by Savannah River Nuclear Solutions, LLC under Contract No. DE-AC09-08SR22470 with the U.S. Department of Energy. The United States Government retains and the publisher, by accepting this article for publication, acknowledges that the United States Government retains a non-exclusive, paid-up, irrevocable, worldwide license to publish or reproduce the published form of this work, or allow others to do so, for United States Government purposes. 


\section{Issues Associated with Safe Packaging and Transport of Nanoparticles}

\author{
Allen C. Smith \\ Savannah River National Laboratory \\ Savannah River Nuclear Solutions \\ Aiken, South Carolina 29808 \\ (803) 279 9409, acdocsmith@aol.com
}

\author{
Narendra Gupta \\ Savannah River National Laboratory \\ Savannah River Nuclear Solutions \\ Aiken, South Carolina 29896 \\ (803) 725 5300, nick.gupta@srnl.doe.gov
}

\begin{abstract}
Nanoparticles have long been recognized a hazardous substances by personnel working in the field. They are not, however, listed as a separate, distinct category of dangerous goods at present. As dangerous goods or hazardous substances, they require packaging and transportation practices which parallel the established practices for hazardous materials transport. Pending establishment of a distinct category for such materials by the Department of Transportation, existing consensus or industrial protocols must be followed. Action by DOT to establish appropriate packaging and transport requirements is recommended
\end{abstract}

\section{BACKGROUND}

The ASTM Committee on Nanotechnology has defined a nanoparticle as a particle with lengths in two or three dimensions between 1 and 100 nanometers $(\mathrm{nm})$. Nanoparticles can be composed of many different base materials and may be of different shapes including: nanotubes; nanowires; and crystalline structures such as fullerenes and quantum dots.

Nanoparticles have been recognized to be hazardous substance from early in their development. This is because of their size and reactivity, chemically, physically and biologically. The primary routes of exposure for nanoparticles are inhalation, dermal absorption, and ingestion. The form of the nanoparticles will play a large role in the exposure potential. For example, a nanoparticle or nanomaterial in powdered form will present a larger inhalation hazard potential than a nanoparticle in suspension. A significant body of literature has developed addressing hazards associated with manufacture and application of nanoparticles, e.g., References 1 through 5.
Packaging and transportation are essential aspects of manufacture and employment of nanomaterials. In spite of the potential hazards associated with nanomaterials, they are not at present listed and hazardous substances under the Hazardous Materials Regulations of Title 49 of the U. S. Code of Federal Regulations, Reference 6. That is, they are not treated as separate, distinct hazards under to provisions of 49CFR170 180.

\section{TERMINOLOGY}

The ASTM Committee on Nanotechnology has defined the terms related to the nanotechnology. The terms "packaging of nanoparticles" and "transportation of nanoparticles" have quite different meaning compared to what we are addressing in this paper. An internet search on "packaging of nanoparticles" comes up with articles that describe how the nanoparticles are used in food packagings or packages used in medical containers. The concern there is the migration of nanoparticles from the packages into food or the medicines and cause safety concerns. Similarly an internet search on "transportation of nanoparticles" comes up with articles that describe how the nanoparticles, suitably packaged individually, can be transported or delivered through bloodstream to specific organs in the human body. It appears that the physical transport of bulk quantities of nanomaterials from one geographical location to another is not a concern in the industry. But considering the toxicity of the nanoparticles, specially the smaller nanoparticles, packaging and transportation of bulk quantities of nanomaterials should be valid concern. This paper addresses some considerations that should be given in formulating the regulatory requirements and guidelines.

The United States Government retains, and by accepting the article for publication, the publisher acknowledges that the United States Government retains, a non-exclusive, paid-up, irrevocable worldwide license to publish or reproduce the published form of this work, or allow others to do so, for United States Government purposes. 


\section{NANOPARTICLE USAGE AND TOXICITY}

Nanoparticle applications are found practically in every group of industry, e.g. cleaning products, cosmetics, food and food- packaging, milling machines, paints, paper, pharmaceutical products, plastics, powder-production, printing and packaging, microelectronics, sensors, surfaces, coating, textiles, watches/optics. In a telephone survey conducted in Switzerland, it was found that the quantities of nanoparticles used in the industry vary from a few grams to up-scaled productions with hundreds of tons. ${ }^{[10]}$ The majority of nanoparticle applications are on a small production scale of less than $100 \mathrm{~kg} /$ year. Up-scaled production in tons per year is found for nanoparticles of $\mathrm{Ag}, \mathrm{Al}-\mathrm{Ox}, \mathrm{Fe}-\mathrm{Ox}, \mathrm{SiO}_{2}, \mathrm{TiO}_{2}, \mathrm{ZnO}$, and carbon black. The nanoparticle sizes for these large productions varied from $100 \mathrm{~nm}$ to $1 \mu \mathrm{m}$. This finding comes as a surprise because the nanoparticles are typically classified having size smaller than $100 \mathrm{~nm}$. This shows that the production of smaller size nanoparticles is still not very prevalent. This could be attributed to the difficulty in maintaining consistency in production for the small size particles. The lack of production of small size nanoparticles may also explain the insensitivity of the industry and regulators to develop packaging and transportation standards. However, the beneficial application of small size particles in the field of drug delivery is well recognized and it would not be long before the production of small particles become common.

The toxicity of the nanoparticles depends on their size, shape and composition. In general, smaller the particle more toxic it is due to their greater propensity of being absorbed or ingested into the blood stream. Smaller size also means the particles have greater chance of leaking through a containment system. Since the use of nanomaterials is increase in the industry, the development of transportation regulations and guidelines for the bulk quantity of nanoparticles is an important consideration.

\section{HAZARDOUS MATERIALS (HAZMAT) PACKAGING AND TRANSPORT}

The packaging and shipment of hazardous materials involves a range of activities and issues. These fall into four broad topics:

- Establishment of degree of hazard.

- Definition of Packaging which addresses the hazards.

- Establishment of appropriate transportation practices.

- Specification of topic specific regulations.

\section{ESTABLISHMENT OF DEGREE OF HAZARD}

Hazardous materials vary in the nature and consequence of their harmful effects to the public, individuals working with the material, and the environment. Classification of the hazard so that more stringent controls are employed for highest hazard materials is essential to rational and economical handling and transportation practices.

The three Classes of highly hazardous materials, Chemical, Biological and Nuclear, provide examples of categorization by degree of hazard. For example, the effects of uptake or exposure to radionuclides have been studied and the quantity of each nuclide which meet an established threshold of harm has been determined, by the International Commission on Radiological Protection. These amounts are designated by $\mathrm{A}_{1}$ and $A_{2}$ values for each radionuclide. The values are tabulated in the Regulations (e.g., Table A-1 of 10CFR71), and determine the required level of package integrity for shipment of the radionuclide.

Small amounts of relatively low hazard materials may be shipped in robust, industrial packagings, because a complete release of the entire contents would not be life threatening to the public, first responders, or the public. Significant amounts of a highly hazardous radionuclides must be transported in leak tight, performance tested, engineered packagings which have been granted a Certificate of Compliance by the Department of Transportation, the Nuclear Regulatory Commission or the Department of Energy.

Requirements of packaging and shipment of infectious substances and toxic chemical agents are similar. The level of risk of a material is determined and characterized, based on lethality studies. The requirements for packaging and shipment of the materials are commensurate with the hazard of the contents. The DOT regulations establish requirements for packages dependent upon level of hazard, classifying them as Packaging Group 1, Packaging Group II, etc., packages.

\section{PACKAGING REQUIREMENTS}

Regardless of whether the hazardous material is one of the highly hazardous materials or not, the Transportation Regulations require safe and adequately robust packaging, appropriate to the contents. The common requirement of all hazardous materials packagings is containment or confinement. The packaging must prevent loss or dispersion of the contents during normal or accident conditions which may occur in transport. The level of containment required depends upon the degree of hazard of the contents and its form. A single solid piece of a material, even though potentially toxic, would typically not be as great a hazard as the same amount of that material in powder form, which could be dispersed in the event of a packaging failure.

Containment is demonstrated by leakage testing of the packaging, both under normal conditions and following any qualification testing, representing hypothetical accidents. Accordingly, the packagings must be designed to be leak tight and to be leak testable, using the methods defined by ANSI Standard, N14.5. 
For the package to withstand the physical challenges encountered in normal transport conditions and severe transportation accidents, the packaging must be designed and tested to meet these requirements. The Regulations (49CFR170-180 and 10CFR71) establish performance standards for hazardous materials packagings. The requirements for packaging for radioactive materials are very demanding and provide a good example. A graded approach is established, with less stringent packaging requirements of low hazard contents (less than an A1 or A2 amount), designated as Type A packages. For contents greater than this, designated Type B contents, rigorous standards are established. A Type B radioactive materials package must withstand a sequence of water spray, drop, puncture, stacking tests as part of the Normal Conditions of Transport test sequence. The packaging must then withstand a sequence of Hypothetical Accident Conditions tests consisting of:

- 9 meter free drop onto an hard, immovable surface.

- 1 meter free drop onto a puncture pin, $10 \mathrm{~cm}$ in diameter.

- 30 minute exposure to all engulfing, $800^{\circ} \mathrm{C}$, jet fuel fire.

Some small packages with high risk contents must be subjected to a crush test. In this event the package is placed on the hard, immovable surface and crushed by a $500 \mathrm{~kg}$ plate, dropped from a height of $9 \mathrm{~m}$.

In addition, an undamaged example must be subjected to an immersion test.

It is worthy of note that the package must maintain containment through the sequence of tests. The thermal test requirements are of particular for finely divided materials, since the fire plume provides a highly effective means of dispersal of such material in the event of loss of containment.

\section{TRANSPORTATION PRACTICES}

In addition to employing an acceptable packaging for the contents, the package must be marked to correctly identify the contents, and shipped with proper shipping papers. Shipping papers identify the material, shipper and receiver and provide information needed in the event of an accident by the responding authorities.

The conveyance must be marked to identify the hazardous contents. The type and location of placards for hazardous materials are defined in the Regulations. Transportation regulations require segregation of packagings for some materials and prohibit shipment of some combinations of materials on the same conveyance.
For shipment in commerce, guidance for first responders to accidents (police and firemen) is prepared and training courses developed and offered.

\section{QUALITY ASSURANCE}

The means for assuring that the various requirements are met is an effective Quality Assurance program. For radioactive materials, shippers QA program must meet the requirements of Sub Part H of 10CFR71 and be approved by the NRC.

\section{TRANSPORTATION OF NANO MATERIALS}

Even though the Hazardous Materials Regulations do not, so far, address nanomaterials as a separate, distinct category, they are recognized as hazardous and generally fall within one of the existing Classes of hazardous substances (i.e., toxic, flammable, or reactive). The applicable requirements must be met for shipments in commerce. Nanomaterials that do not meet fall within DOT established hazardous materials categories, may pose health and safety hazards to anyone who is exposed to them, and should be handled and shipped like any other hazardous material.

Guidance provided by the DOE ES\&H guidelines and in the literature (Reference 4) is appropriate and should be adopted, pending promulgation of specific regulations for nanomaterials. These guidelines follow the outline discussed above for other hazardous materials.

The need for establishing relative hazard values for nanomaterials, similar to the ICRP methods, is recognized in the literature and appears to be the subject of much study. Pending development of a basis for a graded approach, all nanomaterials may have to be treated as highly hazardous.

The need for suitable packaging is recognized, with Packaging Group I containers being recommended.

The need for the primary (inner) container to be tightly sealed is noted, but no measureable leak-tightness requirement is proposed. The use of tape or other means of preventing a removable closure from inadvertently opening in transport is specified.

The primary container is to be contained in a protective overpack with a robust outer container, with sock absorbing material provided to locate the primary container and protect it from damage. If needed, the overpack material(s) should be able to absorb any liquids which might leak in transport.

Shipping papers and package markings should meet DOT requirements. In particular, the primary (inner) container should be have a label that identifies the material as Nanomaterial, and provides cautionary information and contact information for the individual designated as point of contact. 


\section{RECOMMENDATIONS}

Establishment of a measure of relative hazard for various nanoparticles or nanomaterials would enable employment of a graded approach, where the level of packaging would be consistent with the level of hazard of the contents.

For materials that are combustible, fire would be expected to consume the material. For noncombustible particles, fire plume could disperse the nanomaterial. Accordingly, a packaging for nanomaterial must be able to withstand a fire (i.e., maintain containment during and after a fire).

Materials that are bioactive in an aquatic environment must be packaged to withstand immersion and hydrostatic crushing.

\section{CONCLUSIONS}

Nanoparticles are recognized as hazardous materials that must be shipped in accordance with Department of Transportation Regulations.

Establishment of a practice of characterizing relative hazard is anticipated. Such a practice will enable adoption of a graded approach to packaging for nanoparticles. For any nanoparticles which are highly hazardous, engineered, performance based packaging must be employed.

The practice of using DOT Packaging Group I packagings provides an acceptable level of protection for the public, workers and environment.

\section{CONTRACT NUMBER}

This document was prepared in conjunction with work accomplished under Contract No. DE-AC09-08SR22470 with the U.S. Department of Energy.

\section{DISCLAIMER}

The United States Government retains, and by accepting the article for publication, the publisher acknowledges that the United States Government retains, a non-exclusive, paid-up, irrevocable, worldwide license to publish or reproduce the published form of this work, or allow others to do so, for United States Government purposes.

This work was prepared under an agreement with and funded by the U.S. Government. Neither the U. S. Government or its employees, nor any of its contractors, subcontractors or their employees, makes any express or implied: 1 . warranty or assumes any legal liability for the accuracy, completeness, or for the use or results of such use of any information, product, or process disclosed; or 2. representation that such use or results of such use would not infringe privately owned rights; or 3 . endorsement or recommendation of any specifically identified commercial product, process, or service. Any views and opinions of authors expressed in this work do not necessarily state or reflect those of the United States Government, or its contractors, or subcontractors.

\section{REFERENCES}

1. ASTM Standard E2535-07, Standard Guide for Handling Unbound Engineered Nanoscale Particles in Occupational Settings, September, 2007.

2. Brouwer, D., van Duuren-Stuurman,B., Berges, M., Jankowska, E., Bard, D., Mark, D.,'From workplace air measurement results toward estimates of exposure? Development of a strategy to assess exposure to manufactured nano-objects", Journal of Nanoparticle Research, (2009) 11:1867-1881.

3. U.K. Department for Environment, Food and Rural Affairs, Characterising the Potential Risks posed by Engineered Nanoparticles, Research Report, December, 2007.

4. Amoabediny, Gh., Naderi, A., Malakootikhah, J., Koohi, MK., Mortazavi, SA., Naderi, M., Rashedi, H., "Guidelines for Safe Handling, Use and Disposal of Nanoparticles", Nanosafe 2008: International Conference on Safe production and use of nanomaterials, Journal of Physics: Conference Series 170 (2009).

5. U.S. Department of Energy, Approach to Nanomaterial ES\&H, Rev. 3a, May 2008.

6. U.S. Code of Federal Regulations, Title 49, Transportation, Parts 170-178, Hazardous Materials Regulations.

7. U.S. Code of Federal Regulations, Title 10, Part 71, Packaging and Transportation of Radioactive Materials, January, 2004.

8. ANSI N14.5 - 1997 American Standard for Radioactive Materials - Leakage Tests on Package for Shipment, ANSI, 1998.

9. ASTM E2456-06, "Standard Terminology Relating to Nanotechnology".

10. Kaspar Schmid and Michael Reidiker, Use of Nanoparticles in Swiss Industry: A Targeted Survey, Institute of Work and Health, University of Lausanne and Geneva Lausanne, Switzerland, 2008. 